\title{
Thinking Styles and Professional Choice Satisfaction of Social Profile Students: Implications for Academic Achievement in University
}

\author{
Kristina Kovalcikiene, Loreta Buksnyte-Marmiene \\ Vytautas Magnus University, Kaunas, Lithuania
}

\begin{abstract}
The aim of this study was to investigate the predictive power of thinking styles and satisfaction with professional choice for academic achievement. A total of 395 first-year social profile students in the economics and management (18\%), political science and diplomacy (11.9\%), social sciences (40\%), and law (30.1\%) faculties at Vytautas Magnus University in Lithuania completed the TSI (thinking styles inventory), and reported the GPA (grade point average) and satisfaction with professional choice. Hierarchical multiple regression analysis indicated that hierarchic and internal thinking styles together with professional choice satisfaction predicted higher GPA. These results suggest that those social profile students who distribute attention to several tasks that are prioritized according to one's valuing of the tasks (hierarchic style), work on tasks that allow one to work as an independent unit (internal style) and are satisfied with the professional choice, produce higher academic achievement. Implications of these findings for university educational and career counsellors and for faculty teachers are presented.
\end{abstract}

Keywords: thinking styles, academic achievement, professional choice satisfaction, social profile students

\section{Introduction}

A constructive contribution to the maximal achievement of the academic potential of students is essential condition to improve the education in universities. Of late years, the investigation of thinking styles has gained widespread recognition and, according to Kozhevnikov (2007), has reached an impasse. Thinking styles aroused great interest in educational psychology. Research conducted by Sternberg and Zhang, and works of others (e.g., Bernardo, Zhang, \& Callueng, 2002; Betoret, 2007; Cano-Garcia \& Hughes, 2000; Cilliers \& Sternberg, 2001; Gurpinar, Alimoglu, Mamakli, \& Aktekin, 2010; Khasawneh, Abu-Tineh, \& Obeidat, 2006; Kozhevnikov, 2007; Liu, Magjuka, \& Lee, 2008; Luk, 1998; Zhang, 2001, 2002b, 2002d, 2004b, 2006a, 2006b, 2007, 2008; Zhang \& Sternberg, 1998, 2000) visibly show that endeavour to optimize academic performance should give consideration to thinking styles.

As an individual difference variable in human performance, thinking styles (an encompassing term for such style constructs as cognitive styles, learning styles, intellectual styles, or modes of thinking) refer to

Kristina Kovalcikiene, Ph.D. candidate, Faculty of Social Science, Department of Theoretical Psychology, Vytautas Magnus University.

Loreta Buksnyte-Marmiene, Ph.D., associate professor, Faculty of Social Science, Department of Theoretical Psychology, Vytautas Magnus University. 
people's preferred ways of processing information (Zhang \& Fan, 2007) or our preferred comfortable ways of using the abilities that we have (Zhang \& Sternberg, 2005). In other words, thinking styles refer to what a person prefers to do, and how they like to do it (Betoret, 2007). Kozhevnikov (2007) suggested that thinking styles "represent heuristics that individuals use to process information about their environment" (p. 464). According to the author, these heuristics can be identified at multiple (from perceptual to meta-cognitive) levels of information processing. And finally, thinking styles are not the same as abilities but refer to individuals' preferred ways of applying their abilities in cognitive tasks (Bernardo et al., 2002; Zhang \& Sternberg, 2005).

Psychologists have conducted many studies and developed various measurement instruments to determine different thinking styles. In the literature, the Sternberg's TSI (thinking style inventory) has been one of the most commonly used measurement tool among students. Researchers have examined the thinking styles in many variables, including achievement (Bagley \& Mallick, 1998; Bernardo et al., 2002; Cano-Garcia \& Hughes, 2000; Luk, 1998; Zhang, 2001, 2002d, 2004b, 2006a, 2007, 2008; Zhang \& Sternberg, 1998), learning and approach (Betoret, 2007; Zhang, 2004a; Zhang \& Sternberg, 2000), personality traits (Zhang, 2000; 2002c), psychosocial development (Zhang, 2002a), etc.. However, as Betoret (2007) asserted, studies of the relationship between thinking styles and students' satisfaction are scarce. Also, nobody had investigated joint (thinking styles and satisfaction with professional choice) contribution to academic achievement of the students.

\section{Sternberg's Theory of Mental Self-government}

Sternberg proposed theory of thinking styles which he called the theory of mental self-government. The theory uses the structure of government as a metaphor to portray the way the human mind works. Sternberg contended that "just as there are many ways of governing a society, there are many ways of governing or managing our activities. These different ways of managing our activities can be construed as our thinking styles” (Zhang \& Sternberg, 2005, p. 11).

This theory concerns that people need to manage their everyday activities and provide dimensions and characterizations of how people organize, direct, and manage their own thinking activities. The author of the theory offered the multi-dimensional system of thinking styles, proposing 13 thinking styles grouped in five dimensions: function (legislative, executive, and judicial), form (hierarchical, oligarchic, monarchic, and anarchic), level (global and local), scope (internal and external), and leaning (liberal and conservative). According to the theory, thinking styles are value-free and "for the same thinking style can serve on person beautifully in one situation, but may fail the same person miserably in another situation” (Zhang, 2004a, p. 1552).

Although the thinking styles fall into five dimensions, they can be broadly categorized into three groups or categories (Zhang, 2001, 2004a, 2007, 2008; Zhang \& Sternberg, 2000, 2005). The three types of thinking styles are introduced in Table 1.

In general, Type I styles that are more creative and require higher levels of cognitive complexity are related to personality attributes that are traditionally perceived as positive, for example, high levels of self-esteem, deep approach to learning, high cognitive developmental levels, holistic modes of thinking, openness to experience, better-developed sense of identity, and strong sense of purposefulness. Conversely, Type II styles that suggest favoring of norms and denote lower levels of cognitive complexity are related to personality attributes that are traditionally considered as negative, for example, low self-esteem, low cognitive 
developmental levels, analytic modes of thinking, neuroticism, pessimism, poorly integrated sense of self, and lack of sense of purposefulness (Betoret, 2007; Zhang, 2002d, 2004c, 2008; Zhang \& Sternberg, 2005).

Table 1

Description of Thinking Styles

\begin{tabular}{|c|c|c|c|}
\hline Category & Description & Thinking style & Characteristic \\
\hline \multirow{5}{*}{ Type I } & \multirow{5}{*}{$\begin{array}{l}\text { Generate creativity and denote high levels of } \\
\text { cognitive complexity }\end{array}$} & Legislative & Being creative \\
\hline & & Judicial & Evaluative of other people or products \\
\hline & & Global & Focusing on the whole picture \\
\hline & & Hierarchical & Prioritizing one’s tasks \\
\hline & & Liberal & Taking new approaches to tasks \\
\hline \multirow{4}{*}{ Type II } & \multirow{4}{*}{$\begin{array}{l}\text { Suggest a norm-favoring tendency, denote low } \\
\text { levels of cognitive complexity }\end{array}$} & Executive & Implementing tasks with given orders \\
\hline & & Local & Focusing on concrete details \\
\hline & & Monarchic & Working on one task at a time \\
\hline & & Conservative & Using traditional approaches to tasks \\
\hline \multirow{4}{*}{ Type III } & \multirow{4}{*}{$\begin{array}{l}\text { May manifest different aspects of the styles } \\
\text { from either group, depending on the stylistic } \\
\text { demand of the specific task }\end{array}$} & Anarchic & Working on whatever tasks that come along \\
\hline & & Oligarchic & Working on multiple tasks with no priority \\
\hline & & Internal & Working on one's own \\
\hline & & External & Working with others \\
\hline
\end{tabular}

It is interesting that in terms of success in academic performance numerous studies presented the results that Type II thinking styles positively contributed to students' academic achievement, whereas Type I did so negatively (Zhang, 2002d; 2008).

\section{Thinking Styles and Academic Achievement Among Students}

In the field of education, numerous studies have found that thinking styles have implications for academic activities or performance (e.g., Bagley \& Mallick, 1998; Bernardo et al., 2002; Betoret, 2007; Cano-Garcia \& Hughes, 2000; Cilliers \& Sternberg, 2001; Gurpinar et al., 2010; Khasawneh et al., 2006; Liu et al., 2008; Luk, 1998; Zhang, 2001, 2002b, 2002d, 2004b, 2004c, 2006a, 2006b, 2007, 2008; Zhang \& Sternberg, 1998, 2000). Moreover, researchers have found that thinking styles have predictive power for academic achievement beyond general abilities (Zhang, 2001, 2008; Kozhevnikov, 2007).

Luk (1998) investigated the relationship between thinking (originally, "cognitive”) styles and academic achievement in the context of distance learning. The results indicated that field independent (tend to be more analytical and logical) students performed significantly better than field dependent ones (are likely to have a less defined sense of autonomy and independence). The authors confirmed that thinking style differences are very important for students' academic achievement.

The research of Zhang (2001) revealed that certain thinking styles have contribution to academic achievement beyond what was explained by self-rated abilities. For the Hong Kong sample, the preferences for working by oneself (internal) and working with a sense of priority (hierarchical) thinking styles tended to contribute positively to academic achievement. By contrast, the use of the legislative, judicial, and liberal styles tended to put students in an academically disadvantaged position. For the Chinese sample, higher achievement was not positively related to the executive or conservative thinking styles. Moreover, higher achievement was significantly negatively related to the executive thinking style. Zhang (2002d) replicated the study with U.S. (United State) university students. The results of this study revealed that the conservative style positively 
predicted students' GPAs (grade point averages), whereas the global and liberal styles negatively did so.

Bernardo et al. (2002) investigated the relationship between thinking styles and academic achievement among Filipino students. The analysis showed that conservative, executive, and hierarchical thinking styles are related to GPA.

Cano-Garcia and Hughes (2000) also conducted an investigation of the relationships between thinking styles and academic achievement among university students in Spain. The findings from this study also supported those obtained in Hong Kong study. In this study, students that prefer to work individually (internal style), do not enjoy creating, formulating, and planning for problem-solution (legislative in a negative sense) and those that have adherence to existing rules and procedures (executive) were those who obtained higher academic achievement.

Summarizing all studies in this field, it is evident that thinking styles significantly contribute to academic achievement. Most of studies (except the studies in U.S. and Chinese university sample) indicated that the executive, conservative, internal, and hierarchical style contributed positively to academic achievement, whereas legislative and liberal thinking styles contributed negatively to academic achievement. In other words, thinking styles that denote conformity (conservative), respect for authority and rule adherence (executive), preference for working individually (internal), and a sense of order (hierarchical) are positively related to academic achievement of university students. On the other hand, thinking styles that are creativity generating (legislative and liberal styles) are negatively related to academic achievement.

However, there are contradictory results of researches. In addition to previously mentioned studies in America and Chinese, another empirical study that should be mentioned is conducted by Liu et al. (2008). Authors revealed that thinking styles may be a poor indicator of students' overall learning performance. Also, Zhang (2007) found that conservative thinking style predicts better achievement among students in lower grade levels, whereas creative styles contribute to achievement among students in higher grade levels. Hence, the question remains completely unanswered whether and which thinking styles may be predictors of academic achievement.

\section{Thinking Styles, Satisfaction With Professional Choice and Academic Achievement}

No studies were conducted where all three constructs (thinking styles, satisfaction with professional choice, and academic achievement) were taken into account. Why does satisfaction with professional choice play an important role in the link between thinking styles and academic achievement? The answer is that students' satisfaction brings students' success. A satisfied student not only demonstrates better academical results (Zhu, 2012; Gurpinar et al., 2010), but also, direct link exists between satisfaction of the activity and behavioral intentions to continue that activity in the future (Kahn \& Nauta, 2001). Besides, students' satisfaction with their academic majors is positively associated with career decision self-efficacy and negatively associated with career choice anxiety and generalized indecisiveness (Nauta, 2007).

The importance of students' satisfaction at higher educational institutions is non-negotiable. Satisfaction is a relevant measure because other factors being equal, satisfied individuals are likely to be willing to demonstrate more effort than unsatisfied students (Tessema, Ready, \& Yu, 2012).

Satisfaction is defined as the psychological state, which results from confirmation or disconfirmations of expectations with the reality (Liu \& Wang, 2007). In the context of education, students' satisfaction is a short-term attitude based on students' subjective evaluations of their experience with the education service 
supplied (Elliott \& Healy, 2001).

Satisfaction is a well researched topic in academic setting. Students' satisfaction has been conceptualized in a several aspects (for example, as satisfaction with experience, satisfaction with instruction, satisfaction with advising, satisfaction with courses, satisfaction with assessment, satisfaction with an academic department, etc.) (Tessema et al., 2012). In this study, satisfaction is conceptualized as "satisfaction with professional choice". Satisfaction with professional choice refers to the extent to which students perceive themselves as being well decided for the way of their career. In other words, satisfaction with professional choice shows the subjective evaluation of the choice experience.

Personality characteristics are very important for selecting a profession. The whole of person's typological peculiarities determine one's inclination to some certain type of activity. The importance of self-cognition in the process of professional choice is evident, because a person understands who he is and how successfully he will be able to work in a chosen professional sphere (Dubinas, 2006). When a person evaluates situation as unfavorable, the decision to abandon it or not depends on the personality characteristics (Steinmayr \& Spinath, 2008).

All person-environment fit theories emphasize congruence between the requirements of environment and personality. An individual will feel perfect in the conditions suitable for him and uncomfortable if conditions do not correspond to his personality. If there is congruence between environment (e.g., profession) and personality, the chosen profession will be more stable and successful; there will be better learning results and greater satisfaction with the work (Dubinas, 2006).

Betoret (2007) examined the effect of students' and teachers' thinking styles on students' course satisfaction and their learning process. The results revealed that both teachers' and students' thinking styles are good predictors of students' course satisfaction and their involvement in the learning process.

Gurpinar et al. (2010) investigated the relation between learning styles and satisfaction with different instruction methods as well as academic achievement. The results showed that students, who are interested in abstract concepts, use logic to define problems, and then create theoretical models for planning (assimilating style) demonstrated higher satisfaction with traditional training and success in theoretical block exams.

\section{Overview of the Present Study}

The aim of the present study was to investigate the predictive power of students' thinking styles and satisfaction of professional choice for academic achievement in Lithuanian setting. It was interesting to test whether university students' thinking styles along with professional choice satisfaction can be used as predictors for higher academic achievement. In fact, several research questions were addressed. First, do students' thinking styles predict academic achievement in Lithuanian context? If this is possible, what are the best predictors? Are they the same compared with the previous studies? And finally, what is the role of satisfaction with professional choice in that prediction?

The necessity of the research is the fact that in previous studies, the predicted relationships between thinking styles and achievement are contradicted (Zhang, 2001; Bernardo el al., 2002). Besides, as mentioned above, there is no study evaluating the possible effect of students' satisfaction with professional choice for the thinking style prediction of academic achievement.

Two predictions were made. First, Type II thinking styles will statistically predict higher academic achievement (compared with Type I and Type III). Second, prediction is that professional choice satisfaction 
will significantly contribute to students’ academic achievement upon thinking styles.

Because of the fact that thinking styles are at least partially socialized (Zhang, 2004b), success in achieving high scores for one subject (e.g., physics) could be different from that for another subject (e.g., psychology). Therefore, in the present study, first-year social profile students were chosen as a sample group, where studying subjects are similar or congeneric.

\section{Method}

\section{Participants}

A total of 395 first-year social profile students (306 females and 89 males) from a large and representative Vytautas Magnus University in Lithuania participated in the research. The participants were from the social sciences (40\%), law (30.1\%), economics and management (18\%), and political science and diplomacy (11.9\%) faculties. The mean age of respondents is 19.5 .

\section{Measures}

Thinking styles. All participants responded to a Lithuanian version of the TSI (Sternberg \& Wagner, 1992). The 104-item inventory measures 13 different styles of thinking, with seven items per scale. For each item, the participants were asked to rate themselves on a 7-point scale ranging from "1" (indicating that the statement did not describe them at all) to "7" (indicating that the statement characterized them extremely well). The TSI was translated and back-translated between English and Lithuanian. In the previous studies, the TSI has proven to be a reliable and valid measure of thinking styles for U.S., Chinese, Hong Kong, Filipino students, etc.. In the present study, the internal consistency reliability coefficients of the scales are generally satisfactory, ranging from the mid 0.50s to the low 0.80s (see Table 2).

Satisfaction with professional choice. The students were asked to evaluate their satisfaction with professional choice in a 10-point scale ranging from 1 ("Completely dissatisfied") to 10 ("Completely satisfied").

Academic achievement. Achievement was evaluated based on GPA reported by the students.

Table 2

TSI Scales: Means, SDs (Standard Deviations), and Cronbach's Alpha Coefficients

\begin{tabular}{lllll}
\hline Dimension & Thinking style & Mean & $S D$ & $\alpha$ \\
\hline \multirow{3}{*}{ Function } & Legislative & 5.02 & 0.82 & 0.749 \\
& Executive & 4.89 & 0.83 & 0.743 \\
& Judicial & 4.74 & 0.85 & 0.775 \\
\hline \multirow{2}{*}{ Form } & Hierarchic & 4.99 & 0.86 & 0.765 \\
& Monarchic & 4.61 & 0.83 & 0.766 \\
& Oligarchic & 4.54 & 0.74 & 0.545 \\
\multirow{2}{*}{ Level } & Anarchic & 4.63 & 0.86 & 0.540 \\
\hline \multirow{2}{*}{ Scope } & Global & 4.48 & 0.75 & 0.640 \\
& Local & 4.34 & 0.77 & 0.629 \\
\hline \multirow{2}{*}{ Leaning } & Internal & 4.60 & 0.93 & 0.757 \\
& External & 4.81 & 1.03 & 0.841 \\
\hline
\end{tabular}




\section{Results}

The mean rating scores for the thinking styles (see Table 3$)$ for the total group $(N=395)$ range between 4.30 and 5.00 positioning this group in levels "Somewhat well" and "Well". The preferred thinking styles for the social profile students within each of the categories are: legislative (function: mean $=5.02$ ); hierarchic (form: mean $=4.99$ ); global (level: mean $=4.48$ ); external (scope: mean $=4.81$ ); and liberal (leaning: mean $=$ 4.72).

Pearson correlations were computed to examine the relationships among thinking styles and academic achievement as well as relationships between thinking styles and professional choice satisfaction. The results are shown in Table 3.

Table 3

Correlations of Thinking Styles With Academic Achievement and Professional Choice Satisfaction

\begin{tabular}{lcccc}
\hline \multirow{2}{*}{ Thinking styles } & \multicolumn{3}{c}{ Academic achievement (GPA) } & \multicolumn{2}{c}{ Professional choice satisfaction } \\
\cline { 2 - 3 } \cline { 5 - 5 } Legislative & 0.082 & 0.109 & 0.088 & 0.080 \\
Executive & 0.107 & 0.036 & 0.137 & 0.006 \\
Judicial & 0.098 & 0.055 & 0.035 & 0.484 \\
Hierarchic & 0.225 & 0.001 & 0.171 & 0.001 \\
Monarchic & 0.024 & 0.646 & 0.045 & 0.368 \\
Oligarchic & 0.016 & 0.756 & -0.006 & 0.899 \\
Anarchic & 0.021 & 0.678 & 0.063 & 0.212 \\
Global & 0.020 & 0.699 & -0.041 & 0.416 \\
Local & -0.016 & 0.756 & 0.029 & 0.564 \\
Internal & 0.155 & 0.002 & 0.065 & 0.197 \\
External & -0.064 & 0.212 & 0.070 & 0.167 \\
Liberal & -0.008 & 0.870 & 0.076 & 0.132 \\
Conservative & 0.044 & 0.391 & 0.041 & 0.417 \\
\hline
\end{tabular}

Three scales of thinking styles were significantly correlated with GPA: hierarchic $(p<0.01)$, internal ( $p<$ $0.01)$, and executive $(p<0.05)$. Also, executive thinking style $(p<0.001)$ and hierarchic thinking style $(p<$ 0.001 ) were significantly correlated with students’ professional choice satisfaction.

Two hierarchical multiple regression equations were formed to test the predictive power of thinking styles and satisfaction with professional choice for academic achievement.

Table 4 shows that the first regression model explained $10.8 \%$ of GPA variance $\left(R^{2}=0.108\right) . F$-value was statistically significant $(p<0.001)$. It shows that regression model fits the data, i.e., according to its variables, academic achievement could be significantly predicted. The regression analysis indicated that hierarchic and internal thinking styles of social profile students predicted higher GPA (see Table 5).

Table 4

Thinking Styles and Satisfaction With Professional Choice as Predictors of Academic Achievement: Models' Characteristics

\begin{tabular}{|c|c|c|c|c|c|c|c|c|}
\hline \multirow{2}{*}{ Model } & \multicolumn{4}{|c|}{ Model summary } & \multicolumn{4}{|c|}{ ANOVA } \\
\hline & $R$ & $R^{2}$ & $R_{\text {adj }}^{2}$ & Std. error & $d f$ & Mean square & $F$ & Sig. \\
\hline 1 & 0.329 & 0.108 & 0.077 & 0.831 & 13 & 2.373 & 3.436 & $p<0.001$ \\
\hline 2 & 0.381 & 0.145 & 0.112 & 0.815 & 14 & 2.945 & 4.433 & $p<0.001$ \\
\hline
\end{tabular}


Table 5

Thinking Styles and Satisfaction With Professional Choice as Predictors of Academic Achievement: Regression Coefficients

\begin{tabular}{|c|c|c|c|c|c|c|}
\hline \multirow[b]{2}{*}{ Variable } & \multicolumn{3}{|c|}{ Model 1} & \multicolumn{3}{|c|}{ Model 2} \\
\hline & $\begin{array}{l}\text { Standardized } \\
\text { coefficients }(\beta)\end{array}$ & $t$ & Sig. & $\begin{array}{l}\text { Standardized } \\
\text { coefficients }(\beta)\end{array}$ & $t$ & Sig. \\
\hline (Constant) & & 20.243 & $p<0.001$ & & 16.711 & $p<0.001$ \\
\hline Legislative style & -0.078 & -0.931 & 0.352 & -0.086 & -1.048 & 0.296 \\
\hline Executive style & 0.048 & 0.607 & 0.544 & 0.022 & 0.278 & 0.781 \\
\hline Judicial style & 0.055 & 0.692 & 0.490 & 0.081 & 1.028 & 0.304 \\
\hline Hierarchic style & 0.286 & 3.966 & $p<0.001$ & 0.244 & 3.415 & $p<0.001$ \\
\hline Monarchic style & 0.014 & 0.196 & 0.845 & 0.025 & 0.340 & 0.734 \\
\hline Oligarchic style & -0.107 & -1.501 & 0.134 & -0.084 & -1.192 & 0.234 \\
\hline Anarchic style & -0.013 & -0.194 & 0.846 & -0.019 & -0.278 & 0.781 \\
\hline Global style & -0.020 & -0.292 & 0.771 & 0.004 & 0.066 & 0.947 \\
\hline Local style & -0.139 & -2.076 & 0.059 & -0.127 & -1.940 & 0.063 \\
\hline Internal style & 0.257 & 2.858 & $p<0.01$ & 0.248 & 2.812 & $p<0.01$ \\
\hline External style & -0.015 & -0.197 & 0.844 & -0.027 & -0.355 & 0.723 \\
\hline Liberal style & -0.138 & -1.683 & 0.093 & -0.157 & -1.942 & 0.053 \\
\hline Conservative style & -0.051 & -0.680 & 0.497 & -0.053 & -0.729 & 0.466 \\
\hline $\begin{array}{l}\text { Satisfaction of professional } \\
\text { choice }\end{array}$ & & & & 0.199 & 3.953 & $p<0.001$ \\
\hline
\end{tabular}

The analysis of the second regression model showed that mentioned thinking styles together with satisfaction of professional choice had better significant predictable value compared with Model 1. Variables of the Model 2 explained $14.5 \%$ of GPA variance. $F$-value change was statistically significant $(p<0.001)$. This indicates that the Model 2 is significantly different from Model 1 . As the Model 2 explains more variation of the data, the model variables (taken together) better predict academic achievement.

The results suggest that higher academic achievement produces the ones that require orientation toward a sense of order (hierarchic) and preference for working independently (internal) and are satisfied with professional choice.

\section{Discussion}

The study results indicated that preferred thinking styles for the first-year social profile students are legislative, hierarchic, global, external, and liberal style. With the exception of the external scope, the profile of students' thinking styles is creativity-generating and denotes high levels of cognitive complexity (Type I, according to Sternberg's theory). It means that social profile students prefer to work on tasks that require creative strategies (legislative style); prefer to distribute attention to several tasks that are prioritized according to one's valuing of the tasks (hierarchical style); prefer to pay more attention to the overall picture of an issue and abstract ideas (global); prefer to work on tasks that involve novelty and ambiguity (liberal); as well as prefer to work on tasks that allow for collaborative ventures with other people (external). All these characteristics are well reflected in the social profile. Whereas people of this profile specialties work with others, usually work with several problems at once in prioritized order, keep pace with new trends in the field, etc.. 
Although students indicated a preference for Type I styles, these styles seldom contributed to students' academic achievement (Zhang, 2002d; 2008). The analysis of the results indicated that hierarchical (Type I), internal (Type III), and executive (Type II) thinking styles are related to higher academic achievement of the university students. Moreover, executive and hierarchical thinking styles are related to students' satisfaction with professional choice.

How do these results compare with earlier findings? In the present study, the significant correlations with the executive, hierarchical, and internal styles were consistent with the findings of the Hong Kong study (Zhang \& Sternberg, 1998; Zhang, 2001), Filipino study (Bernardo el al., 2002), and Spanish sample (Cano-Garcia \& Hughes, 2000), but we found no relationship between the conservative style and academic achievement.

The difference may have resulted from sampling, or it may also be attributed to the prioritizing of thinking styles by the different educational systems in different cultures (Bernardo et al., 2002). The Sternberg's theory of mental self-government supports the idea that different cultures may value some thinking styles over others. So, educational systems in different cultures might promote and encourage thinking styles that are valued by the culture of the society.

The multiple regression analysis indicated that hierarchical and internal thinking styles of social profile students predicted higher GPA and explained 10.8\% of GPA variance. Also, regression analysis showed that mentioned thinking styles along with professional choice satisfaction had better significant predictable value and explained 14.5\% of GPA variance. In comparison with the study of Cano-Garcia and Hughes (2000), prediction of students' academic achievement showed that almost $10 \%$ of the total variance was explained in terms of learning and thinking styles.

The study results show that satisfaction is recognized to be an important means. Taking students' satisfaction into account is relevant, because students' satisfaction with professional choice have unique contribution to academic performance. These results show that not only congruent thinking styles are important for academic achievement, but no less important is whether students are happy with the way they have chosen. However, more studies would be useful relating professional choice satisfaction, thinking styles, and academic success. For example, the analysis of the motives of professional choice would be useful and interesting to explore. Dubinas (2006) investigated the motives for the choice of profession and identified the following: public prestige, the motive of self-recognition, interest for a certain profession, the motive of active communication, the motive of communication limitation, the motive of professional self-realization, etc..

Other direction for future research may be the investigation of academic environment contribution to academic performance. For example, Hameed and Amjad (2011) found that faculty, advisory staff, and the classes have a very significant impact on the students' experience and these positive students' experiences lead to students' satisfaction.

And finally, although this and other studies have shown that thinking styles contribute to academic success, future research is encouraged in this field. Returning to the results of this study, it is interesting to notice that the most preferred thinking style of social profile students is legislative (the style of generating creativity), but correlation and regression analysis showed that this style has nothing to do with higher GPA or satisfaction with professional choice. These interesting findings may show the fact that the professions of social sciences prefer individuals who are predisposed to creativity, but academic performance is better of those who prefer thinking styles that are associated with regarding rules and instructions. Again, this may be caused by educational system, which is bureaucratic enough in Lithuania. However, additional studies are needed. It 
would be interesting to check how the changes of thinking style in the period between the end of school and entering university regarding educational system demands.

Still, despite some limitations of this study, these results may be of great interest to educational psychologists, career counselors, and university teachers.

\section{Conclusions and Implications}

The findings indicated that hierarchical, internal, and executive thinking styles are significantly correlated with academic achievement (GPA). Two of mentioned thinking styles - executive and hierarchical-are significantly related to students' professional choice satisfaction. The social profile students who distribute attention to several tasks that are prioritized according to one's valuing of the tasks (hierarchical style), work on tasks that allow one to work as an independent unit (internal style) and are satisfied with professional choice produce higher academic achievement.

In sum, the results of this study show that in social sciences the following thinking styles are rewarded: internal (preference to work individually) and hierarchical (adherence to prioritizing tasks).

According to Sternberg's theory, students whose thinking styles do not fit with the style most appreciated by the educational situation (methods, tasks, etc.) may be penalized (Betoret, 2007). In other words, students whose thinking styles correspond with the style required by the educational environment will be more successful compared with their colleagues who have other thinking styles that do not correspond with the educational context demands (e.g., the way the course is organized). This suggests that having information about thinking styles of the students is essential for university educators since each style requires different educational materials and forms (Gurpinar et al., 2010).

Psychologists, career counselors, and teachers in university should try to create the conditions in the learning and developmental environment that ensure that above-mentioned thinking styles are taken into account. For example, career counsellors could draw attention to thinking styles when advising individuals on career choices and encouraging successful career development; psychologists could assess thinking styles of those students who fail to learn and identify sources of psychosocial and teaching support available to students; and university teachers should keep in mind that there are characteristic differences among students in the way they prefer to organize and process information, so they could more wisely organize courses, select tasks and methods of assessment.

On the other hand, students' satisfaction should be taken into consideration. If students demonstrate lower levels of satisfaction, it is recommended to find out the sources of dissatisfaction and consider where the improvement could be developed. As Tessema et al. (2012) emphasized, although satisfaction cannot guarantee students' academic success, students' dissatisfaction adversely may impact students' academic performance.

This suggests that without students' thinking styles, satisfaction is also recognized to be an important means for personal success, which in turn may determine institutional effectiveness.

\section{References}

Bagley, C., \& Mallick, K. (1998). Field independence, cultural context and academic achievement: A commentary. British Journal of Educational Psychology, 68, 581-587.

Bernardo, A. B., Zhang, L. F., \& Callueng, C. M. (2002). Thinking styles and academic achievement among Filipino students. Journal of Genetic Psychology, 163(2), 149-163. 
Betoret, F. D. (2007). The influence of students' and teachers' thinking styles on student course satisfaction and on their learning process. Educational Psychology, 27(2), 219-234.

Cano-Garcia, F., \& Hughes, E. H. (2000). Learning and thinking styles: An analysis of their interrelationship and influence on academic achievement. Educational Psychology, 20(4), 413-430.

Cilliers, C. D., \& Sternberg, R. J. (2001). Thinking styles: Implications for optimizing learning and teaching in university education. SAJHE/SATHO, 15(1), 13-24.

Dubinas, V. (2006). The motivation of choice specified professional activities in Lithuania. Management, 11(2), 34-41.

Elliot, K. M., \& Healy, M. A. (2001). Key factors influencing student satisfaction related to recruitment and retention. Journal of Marketing for Higher Education, 10, 1-11.

Gurpinar, E., Alimoglu, M. K., Mamakli, S., \& Aktekin, M. (2010). Can learning style predict student satisfaction with different instruction methods and academic achievement in medical education? Advances in Physiology Education, 34, 192-196.

Hameed, A., \& Amjad, S. (2011). Students' satisfaction in higher learning institutions: A case study of COMSATS Abbottabad, Pakistan. Iranian Journal of Management Studies, 4(1), 63-77.

Kahn, J. H., \& Nauta, M. M. (2001). Social-cognitive predictors of first-year college persistence: The importance of proximal assessment. Research in Higher Education, 42, 633-652.

Khasawneh, S., Abu-Tineh, A., \& Obeidat, O. (2006). The relationship between learning style preferences and academic achievement of the Hashemite University students. Journal of Educational \& Psychological Sciences, 7(3), 8-24.

Kozhevnikov, M. (2007). Cognitive styles in the context of modern psychology: Toward an integrated framework of cognitive style. Psychological Bulletin, 133(3), 464-481.

Liu, X., Magjuka, R. J., \& Lee, S. (2008). The effects of cognitive thinking styles, trust, conflict management on online students' learning and virtual team performance. British Journal of Educational Technology, 39(5), 829-846.

Liu, Y., \& Wang, G. (2007). Inpatient satisfaction with nursing care and factors influencing satisfaction in teaching hospital in China. Journal of Nursing Care Quality, 22(3), 266-271.

Luk, S. C. (1998). The relationship between cognitive style and academic achievement. British Journal of Educational Technology, 29(2), 137-147.

Nauta, M. M. (2007). Assessing college students' satisfaction with their academic majors. Journal of Career Assessment, 15, 446-462.

Steinmayr, R., \& Spinath, B. (2008). Sex differences in school achievement: What are the roles of personality and achievement motivation? European Journal of Personality, 22, 185-209.

Sternberg, R. J., \& Wagner, R. K. (1992). Thinking styles inventory (Unpublished test, Yale University).

Tessema, M. T., Ready, K., \& Yu, W. (2012). Factors affecting college students' satisfaction with major curriculum: Evidence from nine years of data. International Journal of Humanities and Social Science, 2(2), 34-44.

Zhang, L. F. (2000). Are thinking styles and personality types related? Educational Psychology, 20(3), 271-283.

Zhang, L. F. (2001). Do thinking styles contribute to academic achievement beyond self-rated abilities? Journal of Psychology, 135(6), 621-637.

Zhang, L. F. (2002a). The role of thinking styles in psychosocial development. Journal of College Student Development, 43(5), 696-711.

Zhang, L. F. (2002b). Thinking styles and modes of thinking: Implications for education and research. The Journal of Psychology, 136(3), 245-261.

Zhang, L. F. (2002c). Thinking styles and Big Five personality traits. Educational Psychology, 22, 17-31.

Zhang, L. F. (2002d). Thinking styles: Their relationships with modes of thinking and academic performance. Educational Psychology, 22(3), 331-348.

Zhang, L. F. (2004a). Do university students' thinking styles matter in their preferred teaching approaches? Personality and Individual Differences, 37(8), 1551-1564.

Zhang, L. F. (2004b). Revisiting the predictive power of thinking styles for academic performance. Journal of Psychology, 138(4), 351-370.

Zhang, L. F. (2004c). Thinking styles: University students' preferred teaching styles and their conceptions of effective teachers. Journal of Psychology, 13(3), 233-252.

Zhang, L. F. (2006a). Does student-teacher thinking style match/mismatch matter in students' achievement? Educational Psychology, 26(3), 395-409. 
Zhang, L. F. (2006b). Preferred teaching styles and modes of thinking among university students in mainland China. Thinking Skills and Creativity, 1(2), 95-107.

Zhang, L. F. (2007). Intellectual styles and academic achievement among senior secondary school students in rural China. Educational Psychology, 27(5), 675-692.

Zhang, L. F. (2008). Preferences for teaching styles matter in academic achievement: Scientific and practical implications. Educational Psychology, 28(6), 615-625.

Zhang, L. F., \& Fan, W. (2007). Do modes of thinking predict career interest types among Chinese university students? Thinking Skills and Creativity, 2, 118-127.

Zhang, L. F., \& Sternberg, R. J. (1998). Thinking styles, abilities and academic achievement among Hong Kong university students. Educational Research Journal, 13, 41-62.

Zhang, L. F., \& Sternberg, R. J. (2000). Are learning approaches and thinking styles related? A study in two Chinese populations. Journal of Psychology, 134, 469-489.

Zhang, L. F., \& Sternberg, R. J. (2005). A threefold model of intellectual styles. Educational Psychology Review, 17(1), 1-53.

Zhu, C. (2012). Student satisfaction, performance, and knowledge construction in online collaborative learning. Educational Technology \& Society, 15(1), 127-136. 